\title{
5 Creating a Race to the Top
}

\author{
Hierarchies and Competition within the Chinese ICH \\ Transmitters System
}

\section{Christina Maags}

\author{
Maags, Christina \& Marina Svensson(eds), Chinese Heritage in the Making: \\ Experiences, Negotiations and Contestations. Amsterdam: Amsterdam \\ University Press, 2018 \\ DOI $10.5117 / 9789462983694 / \mathrm{CHO} 5$
}

\begin{abstract}
The chapter retraces the impact of the two main intangible heritage policies (ICH) on individuals and communities in the cities of Jiujiang and Changzhou. Although ICH policies are aimed at supporting local cultural work, the chapter shows how local policy implementation facilitates division and hierarchies among local stakeholders, particularly as inscription often depends on good connections to heritage experts and officials. In the competition for inscription, local stakeholders often employ official heritage discourses and heritage expertise to enhance their agency and obtain legitimacy in the heritage-making process, enhancing contestation and conflicts between members within and between local communities.
\end{abstract}

Keywords: intangible cultural heritage, transmitters, policy, discourses, contestation

Through ratification of the 2003 United Nations Educational, Scientific and Cultural Organization (UNESCO) Convention for the Safeguarding of Intangible Cultural Heritage, the People's Republic of China (PRC) has committed itself to set up an institutional infrastructure and adopt policies for the protection of traditional cultural practices. When implementing the UNESCO Convention, the PRC not only established a representative list for intangible cultural heritage, but also set up a Chinese Living Human Treasures system, the so-called intangible cultural heritage (ICH) transmitter system, on all four administrative levels (see Blumenfield as well as Chan in this volume). As a result of governmental promotion and awareness-building, traditional cultural practices which had previously been gauged as 'superstitious' and 
'feudal', were now re-evaluated and relabelled as intangible cultural heritage. Since the mid-200os, an 'intangible cultural heritage fever' (feiyi re) has swept across Chinese society, rekindling public interest in traditional Chinese culture. The fever has also substantiated the wish to participate in local heritagization processes. While the government appropriates ICH as a tool of governance to regulate social order, modernize isolated regions through tourism, as well as increase the public's 'quality' (suzhi) (Oakes 2013), local stakeholders in turn are utilizing governmental ICH policies to enhance their agency within the heritagization process. By participating in ICH policy implementation, ${ }^{1}$ governmental ICH programmes or heritage discourses, local stakeholders are actively striving to obtain a voice in local identity formation and heritage-making.

This chapter enquires into how local stakeholders affected by top-down ICH policy implementation develop individual strategies to enhance their agency and/or contest the top-down policy implementation and outcome from below. To do so, the study comparatively examines how the two main intangible heritage policies, the 'representative ICH items list' and the 'ICH transmitter list', have an impact on individuals and communities in Jiangsu and Jiangxi Provinces, particularly focusing on Changzhou municipality (Jiangsu Province) and Jiujiang municipality (Jiangxi Province). Although these policies are aimed at supporting local traditions and individual cultural work, local implementation of these policies has brought about division and hierarchies among local stakeholders, since only a limited number of local traditions and cultural practitioners may be inscribed on governmental safeguarding lists and thus receive state funding and support. Furthermore, inscription often depends on good connections to heritage experts and officials. Local stakeholders involved, such as cultural practitioners aiming to become an official representative ICH transmitter or locals striving to have their local tradition enlisted, individually employ official heritage discourses and heritage expertise to enhance their agency and obtain legitimacy in the heritage-making process. As a result,

* The author gratefully acknowledges the generous funding support of this publication by the Volkswagen Foundation, issued within its initiative 'Key Issues for Research and Society' for the research project 'Protecting the Weak: Entangled Processes of Framing, Mobilization and Institutionalization in East Asia' (AZ 87382 ) at the Interdisciplinary Centre for East Asian Studies (IZO), Goethe University, Frankfurt/Main.

1 Although an autocracy, non-state actors in the PRC are increasingly able to participate in the policy process (Mertha 2009) by taking part in policy implementation, policy programmes or shaping public discourses (Maags and Holbig 2016). 
competition for inscription leads to contestation and conflicts between members within and between local communities.

\section{Cultural heritage as a playing field for top-down and bottom-up processes}

Power struggles and contestations resulting from ICH policies in China appear to be caused by a mismatch between the predefined goals of a given ICH policy and the outcome of policy implementation. ${ }^{2}$ Yet, the politics surrounding heritage are much more complex than this picture leads us to believe. As heritage is 'a new form of cultural production of the present that takes recourse to the past' (Kirshenblatt-Gimblett 1995: 269), a plurality of economic, political and cultural stakeholders compete with each other to push through their interpretation of the past. Furthermore, each of these actors use their agency and resources to add value to certain historical remains and traditional practices, resulting in tensions over who holds the power to define what cultural heritage is and what it is not (Bendix 2009: 253-260). Yet, as Bendix et al. (2013) remind us, 'It is not simply human actors seeking or wielding power and holding control: The regimes themselves, as realised in unfolding bureaucratic institutions and processes, discipline both actors and their cultural practices into (perhaps) unforeseen dynamics' (2013: 16). While the institutional setting including policies and laws as well as official discourses thus delineate the playing field on which the actors interact, their power struggles and contestations result in unpredictable repercussions for state and society.

These dynamics are produced by the interplay between top-down processes of ICH policy formulation and implementation on the one hand, and bottom-up processes of reimagining and contesting official conceptualizations of heritage on the other. Heritage is an important national symbol which diffuses ideas of the nation, national identities and collective identity, thereby fostering social inclusion but also economic regeneration and localism (Pendlebury 2015:437). As such the state has a vested interest in controlling cultural heritage discourses and means of protection. Laurajane Smith has pointed out that the official or 'authorized heritage discourse' inherent in the various international heritage conventions which forms the

2 A discrepancy between policy design and policy implementation is a common phenomenon. Policy scholars therefore employ policy implementation and evaluation theories to examine why and how these discrepancies occur (Mazmanian and Sabatier 1980). 
basis of domestic policies, in fact also authorizes institutions of heritage to create or identify a community of cultural practitioners, conservationists and experts (2006: 113). Top-down processes thus not only stipulate what heritage is (or is not) but also who is provided with the opportunity to represent and speak for it. Non-official stakeholders, however, are not passive receivers but active participants in these heritagization processes. Due to this reason, 'contestation is at the core of numerous discourses about heritage, be it in the commemoration of past violence, ancient greatness or everyday life' (Schramm 2015: 443). Non-state actors use their agency to counter official narratives and demand participation in defining cultural heritage, to the extent of mobilizing public opinion to challenge authorized discourses and influence policy making (Cooper 2013; Neil 2015: 348). In this act of 'heritage from below', Robertson has argued that 'anti-hegemonic possibilities do exist and exist as resources for expressions of identity and ways of life that run counter to the dominant' (2012: 2). As a result, numerous heritages are imagined and recognized leading to a 'dissonance' in heritage-making (Tunbridge and Ashworth 1995).

In the PRC, this interplay between top-down and bottom-up processes is similarly complex, yet further couched in rapid processes of economic development and social change. A bulk of scholars has demonstrated how top-down processes of policy formulation and implementation have led to the marginalization of vernacular understandings of cultural heritage. Zhu and Li (2013), for instance, have shown how governmental plans for local tourism sites often neglect popular understandings and local participation. Instead, cultural heritage is regarded as a resource by which the local government can develop the tourism industry and generate revenue (see also Su 2010; Wang and Bramwell 2012), thereby exerting cultural authority through tourism (Oakes and Sutton 2010:4). Top-down regulations similarly commodify and relabel Chinese ICH. In his analysis of the Gwer Sa La Festival in Southwest China, Liang (2013), for instance, has shown how the local government has purposefully created false 'primitive' imaginaries of local ICH in order to inscribe a local traditional religious festival as ICH. The relabelling of popular religion or 'superstition' as cultural heritage is a common phenomenon in China, aimed at de-politicizing and legitimizing religion (Chau 2005; Gao 2014). In addition to fostering the local economy and administering social control through government heritage regulation and management, we can also observe how the party-state has created their own Chinese 'authorized heritage discourse' (Yan 2015) which is similarly informed by international conventions (Du Cros and Lee 2007:140; Li et al. 2008). Through these top-down processes the Chinese party-state 
develops its own interpretation of Chinese cultural heritage as well as 'appropriate' conservation and safeguarding measures.

Local stakeholders, however, do not always accept this imposition of top-down interpretations, regulations and management procedures by the party-state, but attempt to contest or negotiate official heritage politics. Yu, for instance, has demonstrated that while the party-state enlisted traditional festivals as ICH and thus transformed them into tourist attractions, villagers nonetheless contest the official narratives by independently performing and transmitting rituals in a sacred domain outside of governmental control (2015: 1035). By finding ways to circumvent top-down authoritative measures, local communities demonstrate agency and autonomy in transmitting and further developing their traditional cultural practices. Zhu has similarly found that when the party-state adopted, reinterpreted and applied the Western notion of authenticity, the authentication of heritage became 'a governance strategy to legitimize inclusion and exclusion and to allocate economic, moral and aesthetic values' (2014: 12). Nevertheless, in this specific case the villagers challenged the state-imposed authentication by developing their own meaning and norms in their performance (Zhu 2014:11-12). Moreover, local communities may be empowered through the heritagization process by, for instance, benefitting from the tourism industry (Ingram 2012: 66-70) or by participating in one of the few projects where community participation ${ }^{3}$ is encouraged (Nitzky 2013: 226).

Contestations do not only arise between the state and experts on the one side and local communities on the other, but also within local communities. Svensson has drawn our attention to the competition and conflicts that may arise between local actors which occur since 'villagers might differ on what narratives and buildings are central to the local community and how these narratives should be told' (2006: 29). Chio (2013) furthermore has shown how villages compete against each other for tourism revenue. In other cases, villages have competed against each other for being selected as scenic spots, thereby obtaining the opportunity to represent local heritage and benefit from local tourism (Oakes 2013: 386). The interplay between top-down and bottom-up processes in China, as elsewhere, is thus heavily influenced by constantly changing power relations between local stakeholders such

3 Projects where the community is encouraged to participate in the heritagization process, however, remain to be rare. Not only are many of such projects induced by international NGOs or organizations, the party-state frequently regards participation more as a responsibility to support state policy implementation, rather than enhancing rights and agency of the community (Nitzky 2013: 226; see also Fan 2014). 
as government officials, experts, local businesses, cultural practitioners and the like (see Neil 2015), which all attempt to obtain a voice in local heritagization processes.

This chapter retraces the impact of top-down ICH policies on local nonstate stakeholders by focusing on the arising contestations between local communities and individual cultural practitioners. In particular, this study examines how local stakeholders develop individual strategies to influence top-down selection of the 'ICH items list' as well as the 'ICH transmitters list'. For this chapter, the author conducted over 50 semi-structured interviews and engaged in participant observation in Jiangsu and Jiangxi Province, particularly in Jiujiang and Changzhou municipality. During the fieldwork, the author interviewed local cultural practitioners, ICH officials as well as experts ${ }^{4}$ involved in the selection process to identify how local communities attempt to influence top-down selection of ICH items and transmitters ${ }^{5}$ in a bottom-up manner.

\section{Top-down policy implementation: The ICH items and transmitter lists}

The Chinese ICH regime is largely based on the creation of two inventories or lists: The list of representative ICH items (Feiwuzhi wenhua yichan daibiaoxing xiangmu minglu) and the list of ICH transmitters (Feiwuzhi wenhua yichan xiangmu daibiaoxing chuanchengren). While the 'ICH items list' is similar to the UNESCO's Representative List of the ICH of Humanity and constitutes a selection of Chinese traditional cultural practices, the 'ICH transmitters list' inscribes cultural practitioners who perform these traditional practices - comparable to UNESCO's Living Human Treasures system. Both lists are thus established to raise awareness for ICH protection and support practitioners who embody traditional cultural knowledge (State Council 2005; State Council 2008).

Top-down implementation of these policies on all four administrative levels is the responsibility of the Ministry of Culture and its subordinate

4 In this chapter, the term 'ICH experts' is used to describe the bulk of scholars and professionals who advise the party-state in ICH-related work. As heritage experts create and legitimize the official heritage discourse (Smith 2006), they are included in the analysis. Despite an autocracy, in the PRC experts exert significant influence in ICH policy formulation and implementation (Maags and Holbig 2016).

5 As this chapter is derived from a larger research project on the ICH transmitter programme, particular emphasis was put on the selection process within this programme. 
Figure 5.1 An ICH transmitter in Nanjing

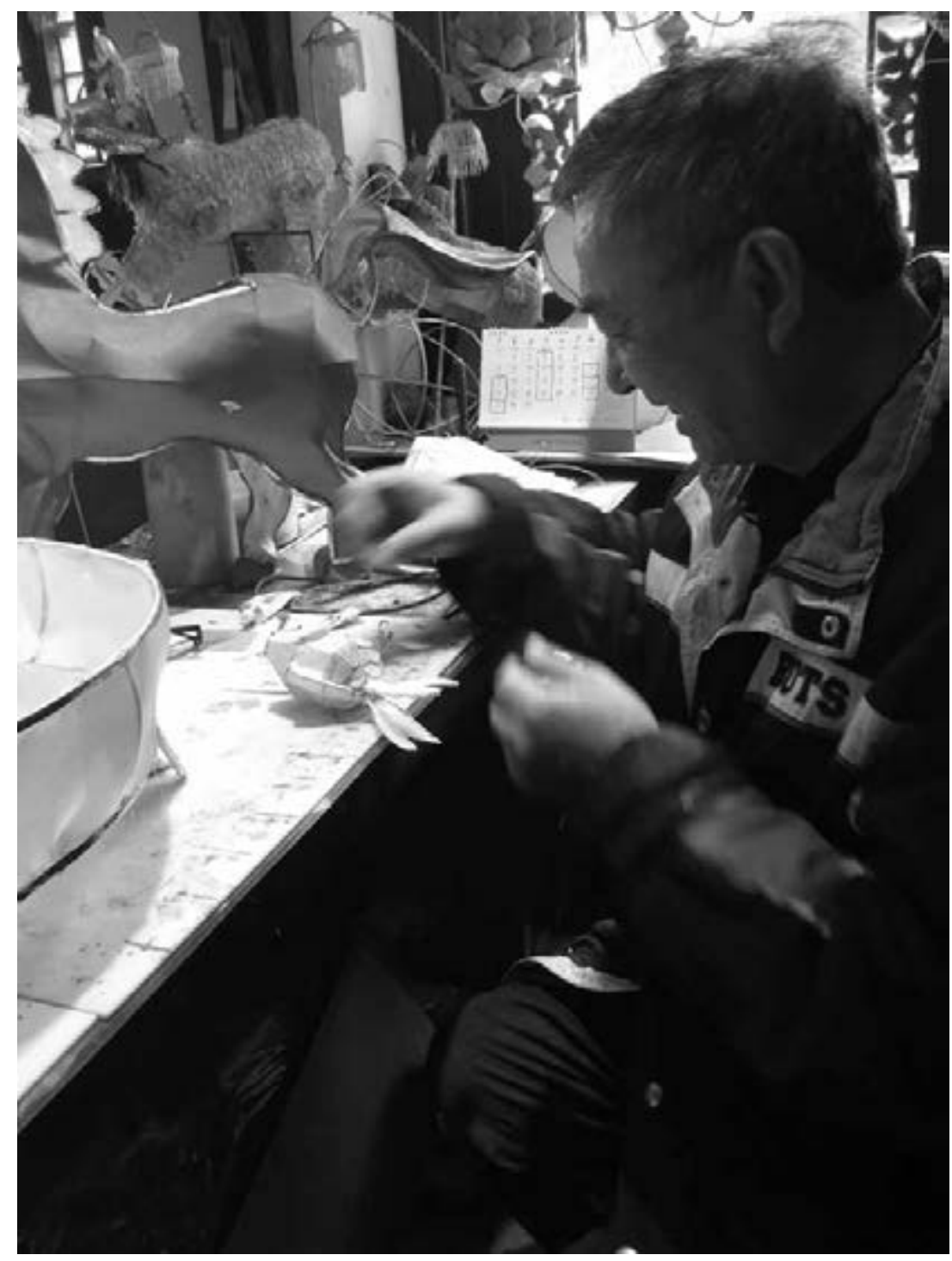

Photograph by Christina Maags

agencies (Ministry of Culture 2008). To date, the Ministry's subordinate agency, the ICH department, has published four national ICH items lists and four ICH transmitters lists (China News 2012). When selecting traditional cultural practices and practitioners for these lists, the Ministry is supported by ICH experts. These experts, such as anthropologists and 
ethnologists, assist the party-state in its ICH-related work by conducting national and regional surveys, compiling dossiers, and recommending certain ICH practices and practitioners for inscription (Shanghai Culture and Broadcasting Department 2010). The local community is, however, not included in the selection process (Interview 6/2014) despite the ICH Convention's stipulation that 'each State Party shall endeavor to ensure the widest possible participation of communities, groups and, where appropriate, individuals that create, maintain and transmit such heritage, and to involve them actively in its management' (UNESCO 2003). While the party-state identifies and selects ICH practices for inscription, cultural practitioners need to apply to become ICH transmitters. If selected for the ICH transmitters programme, they officially receive the title 'ICH transmitter' as well as an annual stipend which is to support the practitioner in transmitting his traditional knowledge to the next generation. In return, the cultural practitioner agrees to teach students, participate in public events and publish on his respective cultural tradition (Interview 15/2015). As the Ministry of Culture establishes lists on all four administrative levels, the ICH items as well as ICH transmitters may be promoted up the ladder, ultimately becoming a national or even international representative of Chinese traditional culture.

Due to the four-tier policy design and implementation structure, the system of ICH lists creates institutional hierarchies between ICH items and ICH transmitters. By selecting certain cultural practices and labelling them 'intangible cultural heritage', the party-state adds value to some practices and practitioners while marginalizing others. As 'one's self-awareness is dependent on the experience of social recognition' (Honneth 2002: 46), selecting certain ICH and cultural practitioners over others and thus recognizing their value through lists leads to exclusion and depreciation of others. Following Thompson, 'political recognition' creates public recognition and becomes a marker of identity, due to which the recognized feels included and equal, while the one not recognized feels overlooked and unvalued (2006: 7-8). While the dynamics around recognition of heritage (Smith 2015) particularly the resulting inclusion and exclusion effects of defining cultural heritage (MacKenzie and Stone 1994; Silverman 2011) through inventories or lists (Hafstein 2009) have long been discussed and criticised, the implementation of these lists along a four-tier system in China further enhances these effects by not only creating competition and contestation over which practice or practitioner is listed (and which is not), but also concerning which ICH is more valuable and thus more eligible to climb the hierarchical ladder. 
As provincial governments enjoy leeway in realizing national policies (Lieberthal and Oksenberg 1988; for an example of the fragmented authority in Chinese heritage administration, see Cui in this volume), ICH policy formulation and implementation differ across provinces. On the one hand, in Jiangsu Province, the provincial culture bureau was quick to adopt its own policies as well as establish ICH items and transmitters lists in 2006 (Jiangsu Culture Department 2006a). Keeping up with provincial objectives, Changzhou municipality has set up four ICH practice lists (Changzhou Culture Bureau 2013a) and four ICH transmitters lists (Changzhou Culture Bureau 2013b). While Jiangsu's provincial government attempts to display a forerunner role in ICH safeguarding through providing financial opportunities such as granting ICH transmitters additional stipends (Jiangsu Culture Department 20o6b), Changzhou's culture bureau has established a strategic partnership with Changzhou University (Interview 19/2015). Due to the provincial aspiration to demonstrate successful ICH safeguarding, according to an ICH transmitter from Changzhou, many opportunities arise for ICH transmitters to take part in international and domestic events and market their products (Interview 18/2015).

Jiangxi Province, on the other hand, has hitherto pursued different objectives. Not only did the provincial government issue its own ICH policy comparatively late in 2015 (Jiangxi Culture Department 2015), it was also rather reluctant to invest in ICH safeguarding as it regards itself as an 'underdeveloped province' (qian fada de sheng) (Interview 48/2015). Nevertheless, Jiujiang municipality has hitherto established five ICH items lists (Jiujiang Culture Bureau 2015) and three ICH transmitters lists (Jiujiang Culture Bureau 2013). Due to their 'underdeveloped' economy, as one ICH transmitter from Hukou, Jiujiang municipality, stated, neither the provincial nor the municipal government pays stipends to their ICH transmitters (Interview 5/2014). Another ICH transmitter from Pingxiang municipality argued that ICH transmitters only seldom have the opportunity to take part in events abroad (Interview 4/2015). Due to the lack of financial support, many ICH transmitters from Jiangxi, therefore, aspire to be inscribed on the national list to obtain the full stipend and additional opportunities that come with national recognition (Interview 26/2015). Whereas the implementation of the ICH items and transmitters lists along the four-tier administrative system already creates an institutionalized hierarchy, the different economic and political circumstances in each province lead to further inequalities between local communities and ICH transmitters' access to opportunities to safeguard local ICH. These 
geographical differences in policy implementation moreover create a greater pressure for local communities and ICH transmitters to have their traditional practices listed on the national level, in order to obtain additional funding opportunities. In competing over inclusion and promotion, local communities and ICH transmitters have developed a variety of strategies to compete for selection which result in conflicts between local communities and practitioners.

\section{Developing bottom-up strategies in heritage competition}

In order to compete in the selection process, local communities and cultural practitioners employ personal contacts (see Chan in this volume), official heritage discourses as well as heritage expertise to get ahead of their competition. In the case of the ICH transmitters list, social connections (or guanxi $)^{6}$ are essential for entering and advancing within the programme. According to an ICH transmitter from Nanjing (Jiangsu Province), many of the 'higher ranking' ICH transmitters obtained the title during an early phase of the programme when it was still quite unknown. They were able to do so as the cultural practitioners knew a government official and were able to use their social connections to be inscribed as ICH transmitter. Subsequently, due to their early entry into the programme and their social connections it was easier for them to be promoted to upper levels. This creates comparative disadvantages for other cultural practitioners. The ICH transmitter from Nanjing further argued that after this initial phase it has become increasingly difficult to become part of the programme and subsequently be promoted within the system as competition among the ICH transmitters has become fierce (Interview 15/2015). These findings also correspond with interviews made in Jiangxi Province. In the interviews, ICH transmitters frequently mentioned that local ICH associations, their work unit (danwei) or local scholars informed them about the programme and subsequently supported them in taking part. Thus cultural practitioners who maintain social ties with people or groups of higher social standing such as officials, experts or other cultural elites, may use them to obtain information or be recommended for the programme or, conversely, may be promoted due to personal interests of these more powerful people and groups. In Hukou, a county of Jiujiang, for instance, one local scholar appeared to be a facilitator in this regard as he persuaded at least one local 
opera performer and one producer of traditional tofu products to submit an application. Furthermore, he also assisted them in filing the application (Interview 28-30/2015).

As the scholar frequently advises the local government in their ICH related work and is a member of the selection committee (Interview 28/2015), he is also very familiar with the official heritage discourse. For this reason, the scholar would not only be able to use his heritage-related expertise to assist the cultural practitioners in their application, but may also influence the local government's decision on which cultural practitioner to select for the programme. Similarly, once a cultural practitioner becomes a member of the programme, he or she may employ the official heritage discourse as well as heritage expertise to advance within the programme. In an interview with a local transmitter in Jiujiang, the transmitter stated that he was thinking of inviting a scholar who could advise him in how to fill out his application for promotion within the programme (Interview 27/2015). As the ICH transmitter had already advanced to the provincial level of the programme, he thus sought scholarly expertise to get ahead in the fierce competition over national inscription. While in the example above social ties were used to receive information about or a recommendation for the programme, these ties may also be used to obtain scholarly expertise related to the official discourse.

Secondly, family ties play an important role in being listed as an ICH transmitter. During field research, I found that many of the ICH transmitter's family members and students also become ICH transmitters, resulting in clusters of ICH transmitters among families or schools. Speaking of another ICH transmitter, one national ICH expert, for instance, explained that 'When the programme started it was his grandfather who took part, then it was he himself who participated, followed by his grandson. Afterwards his grandfather's or his friend participated. They are all like this' (Interview 3/2014). Access to the ICH transmitter programme is thus easier for candidates who already have social connections within the programme or know a person who is well versed in the official heritage discourse. Cultural practitioners who have such social connections or are able to employ heritage scholars thus use these resources strategically to be selected for the programme. Conversely, cultural practitioners who do not have these resources are in a comparatively disadvantaged position, ultimately losing in the competition for inscription.

Finally, ICH transmitters and general cultural practitioners use their own financial resources to enhance their standing and voice in the heritage discourse. By publishing articles and books on their traditional cultural 
practice they contribute to the discourse, obtaining agency among their peers. A county-level ICH transmitter in Jiujiang, for instance, explained that he attempts to publish as much as possible on his local cultural tradition. As he, however, does not have a high income and only gets sporadic financial support, he has troubles funding his publications:

I have to tell you that it is hard to obtain money, sometimes they [the government] don't give you any [money], other times they do something in your name, it is difficult to say. [...] I paid for the research myself. All the things that I have written I have paid for myself, not the government. This means everything you research, you finance yourself. (Interview 5/2014)

Conducting research or generating heritage expertise is thus a further strategy which ICH transmitters employ to enhance their agency within the heritage discourse. However, as cultural practitioners often rely on their art or craft to earn their monthly income, it is difficult to obtain a voice in the discourse without sufficient financial resources.

Local communities have utilized similar strategies to influence the selection of local ICH practices for the 'ICH items list'. As they are excluded from selection, they attempt to influence the governmental officials and experts involved in the decision-making process. As one national ICH expert explains, local communities often directly contact the Ministry of Culture or experts in order to convince them to choose a particular ICH practice for the list (Interview 13/2015). As in the case of the ICH transmitters, they do use informal channels to persuade the local governments and involved experts of the value of their particular ICH practice. This finding is in line with $\mathrm{Ku}$ (2014), who has found that local communities in Fujian have hired an ICH expert to compile a dossier on local heritage which could be handed over to the local government. Local communities thus seek to enhance their agency through means of direct persuasion and appropriation of scientific expertise. In doing so, they similarly use their social connections to government officials and experts or financial resources to win the competition of ICH inscription.

According to a Jiangsu Province ICH official, the local community furthermore attempts to influence the ICH nomination and selection in order to preserve their cultural self-esteem:

This happens a lot. It has to do with their cultural self-esteem, ICH is the cultural basis of their life. Naturally, the culture that their own community likes must be the best one, but they do not have any comparison. 
This is a common thing. It is a good thing as it demonstrates their cultural self-confidence and self-esteem. It is a good thing, yet this kind of situation needs to be resolved through [official] procedures. You cannot just say I should change something and then I will change it. This is not possible. (Interview 16/2015)

This statement demonstrates that it is of great importance to members of the local community that their traditional practice is selected as a representative of local ICH. After the government officials and experts collectively review and nominate certain ICH items for the list, they are obliged to publish this nomination list online and provide the general public with the opportunity to respond to this nomination within 20 days (Jiangsu Culture Department 2015). Many members of the local community, however, seem to seek to influence the selection process at an earlier stage, thereby circumventing the formal procedures.

While local communities attempt to influence the local government and experts to select their preferred ICH practice for the ICH items list, also local government officials develop strategies to get ahead in regional competition for ICH inscription. According to an ICH official in Jiujiang, the municipality hired provincial-level experts to assist them in rebranding their local opera performance. As all the surrounding municipalities were home to a local variant of the same opera tradition, the official was eager to make Jiujiang's version of the opera stand out in contrast to the traditional practice of other municipals. The ICH items list had thus created competition between different government agencies. To gain the upper hand in this competition, he therefore invited an ICH expert familiar with the provincial inscription process and the heritage discourse to the municipality. The expert recommended to use an ancient name which was used during the Ming dynasty instead, thereby rebranding the local opera and providing it with a new historical narrative (Interview 6/2014). As a member of the local community, ICH government officials who are commonly also cultural practitioners themselves may also have an intrinsic motivation to develop strategies which will advance their locality's ICH in the regional competition for inscription. Nevertheless, as government officials are evaluated according to their performance in ICH protection (Interview 19/2015), they may also attempt to enhance the municipality's location branding and tourism industry out of personal career ambitions.

All in all, local communities and practitioners develop a number of strategies to get ahead in the competition for inscription on the ICH items and transmitters lists. In doing so, they commonly choose informal channels to 
exert influence on local decision-making, particularly by employing personal connections or contacting involved government officials and experts directly. They furthermore frequently employ the official heritage discourse and heritage expertise in order to legitimize their claim, if need be by investing their own social connections and financial resources. As the individual actors, however, differ in their opinion which ICH practice is to be selected and compete for inclusion in the ICH transmitters programme or the ICH items list, contestations arise which cause conflicts among the local stakeholders.

\section{Local contestation over heritage representation}

Conflicts mainly arise over whose culture is officially recognized as ICH and who financially benefits from inscription. Inscribing a traditional cultural practice on the safeguarding list implies that this traditions is not only considered to be worthy of governmental protection, but it also implies that this tradition will represent the variety of similar local traditions to the wider public, domestically and internationally. The authority over the representation of local ICH, including its meaning and understanding, is therefore of great importance to the ICH transmitters. One ICH transmitter, for instance, argued that his title also provided him with the opportunity to enhance his reputation across China (Interview 22/2015). Domestic and international government-organized exhibitions, performances and media broadcastings facilitate knowledge on the particular ICH practice and advance the esteem of the transmitter. In some cases also foreign universities or overseas Chinese organizations invited ICH transmitters on their own account (Interview 15/2015, 17/2015, 22/2015). Among the interviewees, all provincial- and national-level ICH inheritors and some municipal ICH inheritors (all in Jiangsu) have had the opportunity to demonstrate their ICH abroad at least once (for instance, interviews 14/2015, 15/2015, 17/2015, 21/2015, 22/2015). By being inscribed on one of the ICH lists, ICH items and ICH transmitters thus become the official representative or showcase for a greater variety of similar traditional practices.

This showcasing of selected ICH practices and practitioners does not only have implications for the pride and self-perception of local communities, but may also entail financial ramifications for them. In the case of the ICH transmitters programme, the financial betterment does not result from the annual governmental subsidy but from the opportunity to sell one's traditional cultural products or performance, for instance, as an official Chinese ICH item. In the same way as intangible cultural heritage is exploited as a 
Figure 5.2 ICH transmitter exhibiting and selling his art at an ICH exhibition in Nanchang, Jiangxi Province, 2015

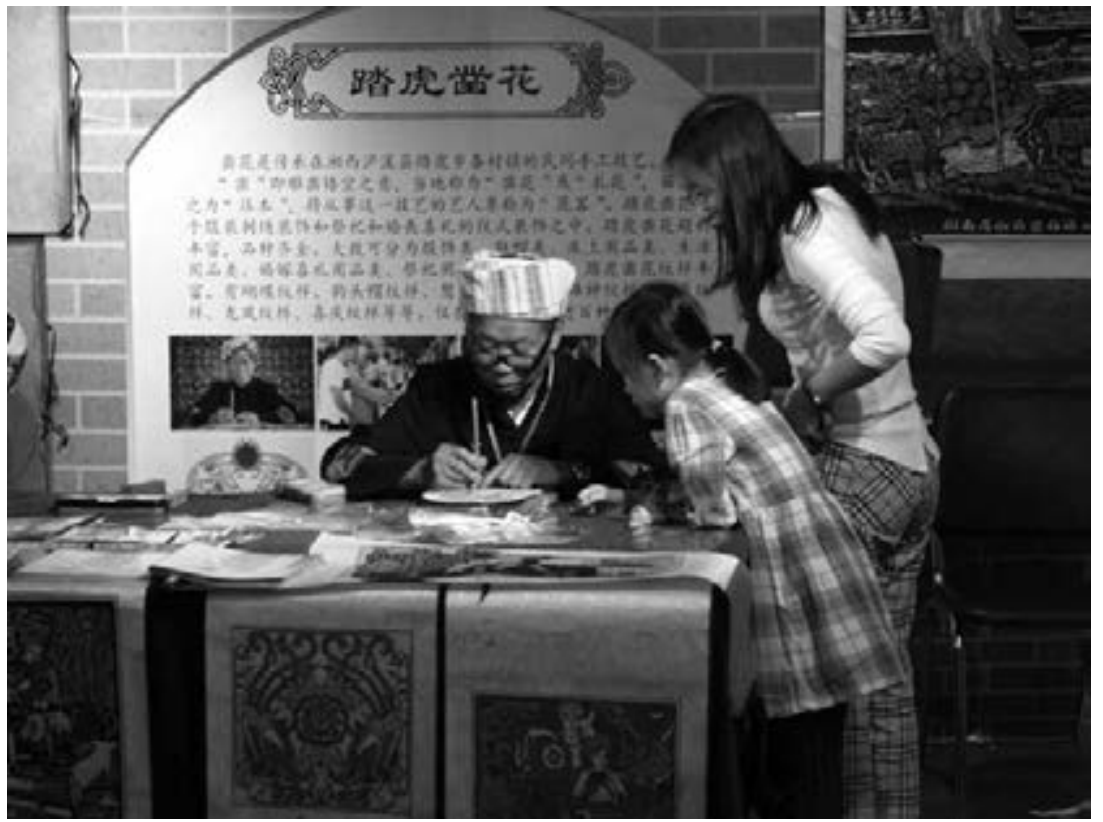

Photograph by Christina Maags

cultural resource (Blake 2009: 64), the title of 'ICH item' or 'ICH transmitter' also becomes a sort of brand or resource which the cultural practitioner can use to sell the ICH he or she is representing - often at a higher price (Interview 26/2015). As a national ICH expert explains, exploiting the ICH label as a brand is a common phenomenon:

It [the food] is perhaps not as famous, but he [the merchant] hangs up a sign saying 'national ICH' and perhaps attracts a few customers. In this instance the merchant is using a branding strategy. [...] This happens all the time. He really uses national ICH in order to earn some money. So he spends a lot of physical and mental efforts to achieve this state. (Interview 7/2014)

Using the official 'ICH transmitter' title as a marketing device has thus the potential of yielding considerable economic benefits. In an interview with a family in Jiujiang producing traditional huangjiu (yellow liquor), the municipal ICH transmitters explained that in some cases cultural products 
by ICH transmitters become so expensive that locals cannot afford the product anymore. The price for regional fenggangjiu (type of liquor), for instance, had risen from 20 to several hundred RMB. When asked whether the price of the liquor they were producing had increased she confirmed, smiled and added that it was not as expensive as fenggangjiu (Interview 26/2015). The 'ICH brand', however, was visible on the bottle as it displayed the Chinese logo for national intangible cultural heritage (see figure 11).

Among the interviewees, a majority confirmed that becoming ICH transmitters had either boosted their sales or led to an increase in product price (Interview 14/2015, 17/2015, 26/2015). In addition, the ICH transmitters also obtain the opportunity to display and sell their products at regional, national or even international events. For this reason, they may not only sell their products at a higher price but may also acquire more customers.

Compared to ICH transmitters, cultural practitioners who are not in the programme do not necessarily have these economic benefits. Both the official recognition and the economic commercialization create a process of exclusion for cultural practitioners not involved in the programme. These cultural practitioners, firstly, do not receive any annual subsidy and, secondly, do not benefit from being able to sell their cultural practice or goods with the help of the 'ICH brand'. While the subsidy does not account for that much of the annual income of any cultural practitioner, when it comes to selling traditional cultural products they find themselves in a position of comparative economic disadvantage. Cultural practitioners not able to use the 'ICH brand' to market their products cannot 'prove' that their products are representing the traditional culture of the region. This leads to a form of exclusion as their products are not necessarily considered 'authentic' representatives of regional ICH, which simultaneously devalues these products.

In competing for selection for governmental lists and programmes, local communities and cultural practitioners therefore contest each other's representativeness and abilities which creates conflicts among them. The practice of selecting a few local practitioners for a programme marginalizes other practitioners leading to arguments and contestations over the listings (Interview 3/2014, 6/2014, 15/2015). One ICH expert, for instance, explained:

Let's say the four of us could have done almost the same thing, we are almost the same and suddenly the media reported on me, I became a celebrity, you three, however, didn't become well-known, this will hurt your self-esteem, then you don't do it anymore, this is not right. (Interview 7/2014) 
Figure 5.3 Liquor bottle with ICH logo produced by ICH transmitter in Jiujiang

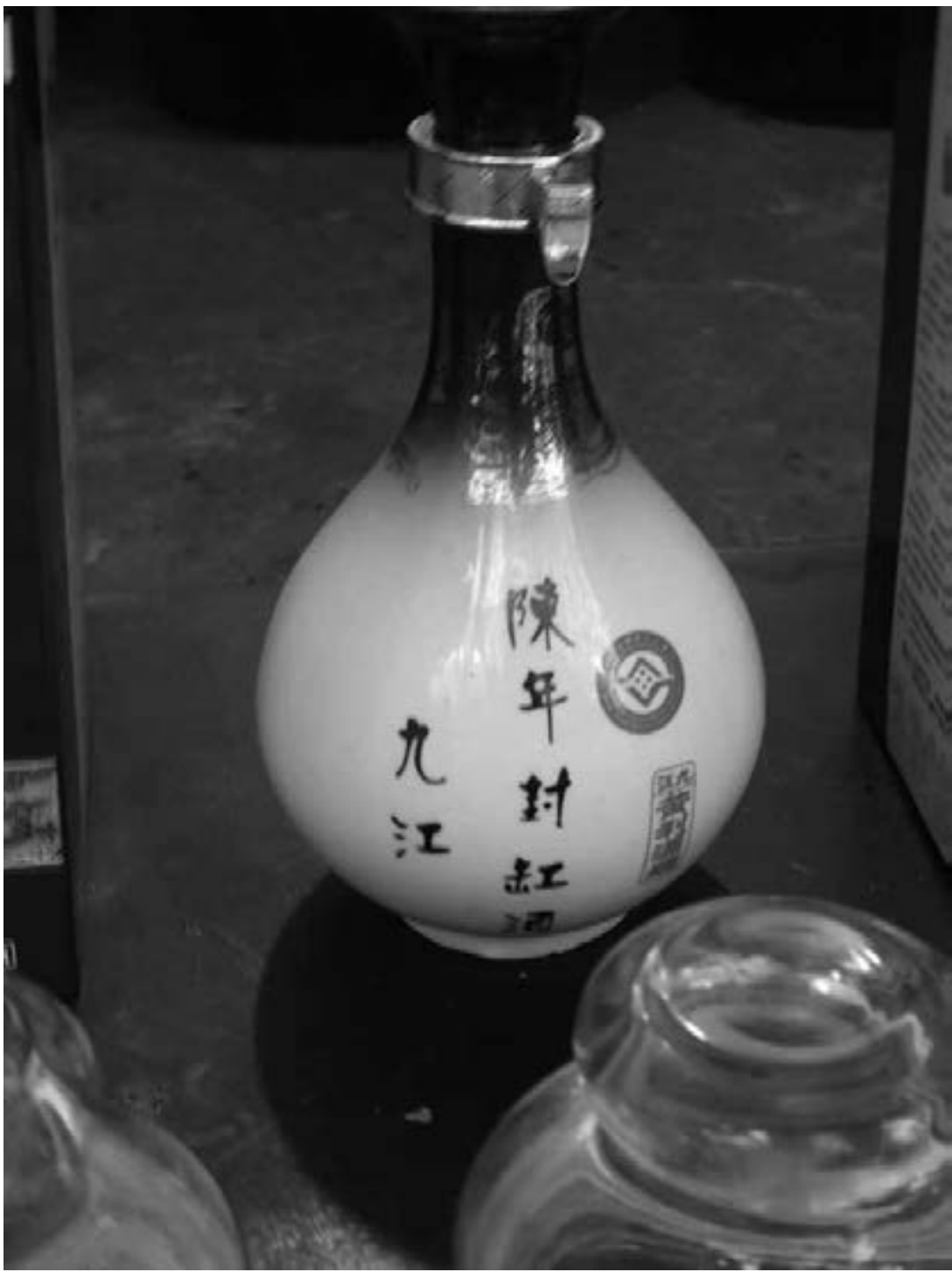

Photograph by Christina Maags

This statement and other conducted interviews demonstrate that in some cases the contestations had even gone so far that some cultural practitioners ceased to perform an ICH practice (Interview 3/2014, 15/2015). These contestations not only occur over who is selected for the ICH transmitters programme but also who advances within the programme. In comparing 
his own abilities to those of a colleague, for instance, one ICH transmitter explained that his colleague, a fellow paper cutter, had expressed jealousy when he was selected for promotion, while the colleague himself was not:

He [paper cutter] is over 80 years old. He told me, 'I have been in this profession for over 60 years and you are much younger than I am. How did you become a national ICH transmitter while I am only a provincial one?' He really felt he had not been treated fairly, so this created a bit of a conflict. (Interview 22/2015)

A majority of the interviewees argued that the non-ICH transmitters were 'jealous' (jidu) of the ICH transmitters' position in society (Interview 18/2015, 22/2015). Although this statement refers to a subjective judgement of the interviewees, it does express potential feelings of exclusion among non-ICH transmitters when their colleague is proclaimed an official representative of local culture and praised as 'outstanding', while they are not. These inclusion and exclusion effects - similar to the observations made with international listings of ICH items at the UNESCO (cf. Kuutma 2007:178) - create hierarchies among cultural practitioners, particularly between the ICH transmitters in the programme, which in turn result in contestations about the representativeness and abilities of the individuals. In addition, not only the abilities as a cultural practitioner are contested but also the way in which one has entered the programme. As stated above, some ICH transmitters obtained the position due to knowing people. As Smith and Waterton (2009) have reminded us, 'heritage is a process through which individuals and collectives negotiate their social position and "place" within particular societies' (2009: 293). In this instance, however, cultural practitioners who are already equipped with social capital or hold a relatively strong societal standing are more frequently selected, leading to reinforcement of the social position of advantaged members of society, while also reinforcing the comparative 'disadvantaged' position of others.

Ultimately, the ICH items and transmitters lists thus lead to the formation of hierarchies and conflicts among cultural practitioners and local communities. Through the selection of particular ICH practices and transmitters, these local communities and cultural practitioners receive the opportunity to generate financial capital (annual stipends, usage of ICH brand, tourism development) and to represent local ICH regionally, nationally and internationally. The majority of the local communities and cultural practitioners, however, do not receive this opportunity. Although their position as such has not been altered, they are now in a place of comparative disadvantage. This finding confirms what Hafstein has argued earlier, namely that 
programmes on ICH safeguarding 'intervene in social processes in order to change them. Safeguarding itself is a change. It is a change in relations' (2007: 81). Identifying certain traditional cultural practices as ICH thus changes the underlying social fabric of society.

\section{Conclusion}

On the basis of a comparison between ICH items and transmitters lists in two different provinces, this chapter has demonstrated that the top-down formulation and implementation of these policies creates hierarchies and division among local communities and cultural practitioners. On the one hand, the policy design listing ICH items and transmitters on four different governmental levels creates an internal hierarchy which leads to a 'race to the top' among the local communities and cultural practitioners eager to inscribe their local traditional practice and climb the institutional ladder. On the other hand, local communities and cultural practitioners whose ICH practice or product is not selected are in the position of a comparative disadvantage. The political and social recognition of heritage thus ultimately creates distinctions between cultural practitioners which have profound impacts on how ICH is transmitted and by whom. While these exclusion and inclusion effects have been similarly mentioned in other studies, the Chinese inscription system for ICH items and ICH transmission stands out as it adds internal competition to these effects in the form of its four-tier inscription hierarchy.

Moreover, due to the prerogative of the government-scholar evaluation committee to select ICH items and transmitters for inscription, the local community does not obtain the right to decide for themselves who is representative of their local ICH. As a result, certain ICH items and transmitters are legitimized as rightful representatives of local culture, thus gaining authority over its meaning and understanding, while the majority of ICH practices and cultural practitioners are excluded. These inclusion and exclusion effects give rise to competition among the local stakeholders involved who develop bottom-up strategies aimed at enhancing their agency within the heritagization process. In competing for inscription, these stakeholders appropriate their personal financial and social resources, particularly their social connections, as well as the official heritage discourse and heritage expertise to gain the upper hand in the competition. As a result, contestations over claims to represent local traditional culture and the opportunity to obtain financial resources arise in a plurality of forms. For these reasons, 
the top down formulation and implementation of the policy seems to not only not enhance the transmission of local traditional culture, but also partly to discourage local practitioners from continuing their work as a whole, as they feel marginalized from their right of cultural representation. Yet, more research is needed concerning which ramifications top-down policy formulation and implementation of so-called 'best practices' in the field of ICH protection have for local stakeholders involved. In particular, more knowledge needs to be generated on how the implementation of ICH policies creates 'windows of opportunities' for local actors to advance their individual agency and which resulting local inclusion and exclusion effects can be observed. In shedding light on these questions, it will become easier to differentiate whether these implications are due to deficiencies in the policy design itself or in the way local stakeholders implement the policy.

\section{References}

Bendix, Regina (2009). 'Heritage between Economy and Politics: An Assessment from the Perspective of Cultural Anthropology', in Intangible Heritage, ed. by Laurajane Smith and Natsuko Akagawa (London: Routledge), 253-269.

Bendix, Regina, Aditya Eggert and Arnika Peselmann (eds) (2013). Heritage Regimes and the States, $2^{\text {nd }} \mathrm{ed}$. (Göttingen: Universitätsverlag Göttingen).

Blake, Janet (2009). 'UNESCO's 2003 Convention on Intangible Cultural Heritage: The Implications of Community Involvement in "Safeguarding”', in Intangible Heritage, ed. by Laurajane Smith and Natsuko Akagawa (London: Routledge), 45-73.

Changzhou Culture Bureau (2013a). 'Changzhou shi zhengfu guanyu gongbu disi pi shiji feiwuzhi wenhua yichan minglu de tongzhi' [Notice by Changzhou municipal government concerning publishing the fourth list of city-level intangible cultural heritage], http://www.js.gov.cn/jsgov/sx/shengxs/changzhous/201305/ t20130515_382726.html.

Changzhou Culture Bureau (2013b). 'Guanyu gongshi disi pi Changzhou shi feiwuzhi wenhua yichan minglu xiangmu de gonggao' [Announcement concerning publishing the fourth list of Changzhou Municipality's intangible cultural heritage items], http://www.changzhou.gov.cn/ns_news/400136625311993.

Chau, Adam Yuet (2005). 'The Politics of Legitimation and the Revival of Popular Religion in Shaanbei, North-Central China', Modern China, 31 (2): 236-278.

China News (2012). 'Guojia feiwuzhi wenhua yichan xiangmu daibiaoxing chuanchengren gongbu gong 1986 ren' [National ICH representative transmitters 
published, in total 1986 people], 25 December, http://news.china.com.cn/ txt/2012-12/25/content_27507667.htm.

Chio, Jenny (2013). 'Good Fences Make Good Neighbours: Claiming Heritage in the Longji Terrace Fields Scenic Area', in Cultural Heritage Politics in China, ed. by Tami Blumenfield and Helaine Silverman (New York: Springer), 143-159.

Cooper, M. (2013). 'Competition and the Development of Authorized Heritage Discourses in a Re-emergent Scottish Nation', in Training and Practice for Modern Day Archaeologists, ed. by J. Jameson and J. Eogan (New York: Springer), 87-104. Du Cros, Hilary, and Y.F. Lee (2007). Cultural Heritage Management in China: Preserving the Cities of the Pearl River Delta (London: Routledge).

Fan, Li (2014). 'International Influence and Local Response: Understanding Community Involvement in Urban Heritage Conservation in China', International Journal of Heritage Studies, 20 (6): 651-662.

Gao, Bingzhong (2014). 'How Does Superstition Become Intangible Cultural Heritage in Postsocialist China?' Positions (Asia Critique), 22 (3): 551-572.

Gold, Thomas, Doug Guthrie and David Wank (2002). Social Connections in China: Institutions, Culture and the Changing Nature of Guanxi (Cambridge: Cambridge University Press).

Hafstein, Valdimar Tr. (2007). 'Claiming Heritage: Intangible Heritage Inc., Folklore (C), Traditional Knowledge ${ }^{\mathrm{rw}}$, , in Prädikat 'Heritage'. Wertschöpfung aus kulturellen Ressourcen, ed. by Dorothee Hemme, Markus Tauschek and Regina Bendix (Berlin: LIT Publishing), 75-100.

Hafstein, Valdimar Tr. (2009). 'Intangible Heritage as a List: From Masterpieces to Representation', in Intangible Heritage, ed. by Laurajane Smith and Natsuko Akagawa (London: Routledge), 93-111.

Honneth, Axel (2002). 'Recognition or Redistribution? Changing Perspectives on the Moral Order of Society', in Recognition and Difference: Politics, Identity, Multiculture, ed. by Scott Lash and Mike Featherstone (London: Sage), 43-56.

Ingram, Catherine (2012). 'Eee, mang gay dor ga ey (Hey, Why Don't You Sing)? Imagining the Future for Kam Big Songs', in Music as Intangible Cultural Heritage: Policy, Ideology and Practice in the Preservation of East Asian Traditions, ed. by Keith Howard (London: Ashgate), 55-76.

Jiangsu Culture Department (2006a). 'Jiangsu sheng feiwuzhi wenhua yichan baohu tiaoli' [Jiangsu Province regulations on intangible cultural heritage protection], http://www.gov.cn/flfg/2006-10/30/content_427298.htm.

Jiangsu Culture Department (2006b). 'Jiangsu sheng feiwuzhi wenhua yichan daibiaoxing chuanchengren mingming yu zizhu zhanxing banfa' [Jiangsu Province's preliminary method for naming and financially assisting representative ICH transmitters], http://feiyi.huaian.com/index.php?m=content\&c=index\&a=sh ow $\&$ catid $=17 \&$ id $=75$. 
Jiangsu Culture Department (2015b). 'Jiangsu sheng wenhuating guanyu disi pi shengji feiwuzhi wenhua yichan minglu tuijian xiangmu mingdan de gonggao' [The Jiangsu Culture Bureau's announcement concerning publishing the fourth provincial list of recommended ICH items], http://www.jscnt.gov.cn/whzx/ tzgg/201510/t20151028_35240.html.

Jiangxi Culture Department (2015). 'Jiangxi sheng feiwuzhi wenhua yichan baohu tiaoli' [Jiangxi Province regulations on intangible cultural heritage protection], http://www.jiangxi.gov.cn/zzc/wjfg/dfxfg/gmhtsqtqybh/201508/ t20150803_1185275.htm.

Jiujiang Culture Bureau (2013). 'Guanyu shenbao disan pi shengji feiyuzhi wenhua yichan xiangmu daibiaoxing chuanchengren de tongzhi' [Notice concerning applying for the third list of province-level representative intangible cultural heritage transmitters], http://www.jxfwzwhycw.com/content.aspx?fd=6\&fn= 工作交流 \&sd $=15 \& s n=$ 公告 $\& a d=241$.

Jiujiang Culture Bureau (2014). 'Guanyu pizhun diwu pi jiujiang shi feiwuzhi wenhua yichan minglu de qingshi' [Instruction concerning approving the fifth list of Jiujiang municipal-level intangible cultural heritage], http://218.65·3.188/ bmgkxx/whj/fgwj/qtygwj/201507/t20150729_1468103.htm.

Kirshenblatt-Gimblett, Barbara (1995). 'Theorizing Heritage', Ethnomusicology, 39 (3): $367-380$.

$\mathrm{Ku}$, Ming-Chun (2014). 'Rethinking "Community” in the Heritagization of Mazu Belief in China', presentation, Conference of the Association for Critical Heritage Studies, Australian National University, Canberra, 2-4 December 2014.

Kuutma, Kristin (2007). 'The Politics of Contested Representation: UNESCO and the Masterpieces of Intangible Cultural Heritage', in Prädikat 'Heritage'. Wertschöpfung aus kulturellen Ressourcen, ed. by Dorothee Hemme, Markus Tauschek and Regina Bendix (Berlin: LIT Publishing), 177-196.

Li, M., B. Wu, and L. Cai (2008). 'Tourism Development of World Heritage Sites in China: A Geographic Perspective', Tourism Management, 29: 308-319.

Liang, Yongjia (2013). 'Turning Gwer Sa La Festival into Intangible Cultural Heritage: State Superscription of Popular Religion in Southwest China', China: An International Journal, 11: 58-75.

Lieberthal, Kenneth, and Michael Oksenberg (1988). Policy Making in China:Leaders, Structures and Processes (Oxford: Princeton University Press).

Maags, Christina, and Heike Holbig (2016). 'Replicating Elite Dominance in Intangible Cultural Heritage Safeguarding: The Role of Local Government-Scholar Networks in China', International Journal of Cultural Property, 23: 71-93.

MacKenzie, Robert, and Peter Stone (1994). The Excluded Past: Archaeology in Education (London: Routledge). 
Mazmanian, Daniel, and Paul Sabatier (1980). 'The Implementation of Public Policy: A Framework of Analysis', Policy Studies Journal, 8 (4): 538-560.

Mertha, Andrew (2009). "Fragmented Authoritarianism 2.0": Political Pluralization in the Chinese Policy Process', China Quarterly, 200: 995-1012.

Ministry of Culture (2008). 'Zhuyao zhineng' [Main functions], People's Republic ofChina, http://www.mcprc.gov.cn/sjzz/fwzwhycs_sjzz/201111/t20111128_341012. htm.

Neil, Cath (2015). 'Heritage and Participation', in The Palgrave Handbook of Contemporary Heritage Research, ed. by Emma Waterton and Steve Watson (New York: Palgrave Macmillan), 346-365.

Nitzsky, William (2013). 'Community Empowerment at the Periphery? Participatory Approaches to Heritage Protection in Guizhou, China', in Cultural Heritage Politics in China, ed. by Tami Blumenfield and Helaine Silverman (New York: Springer), 205-232.

Oakes, Tim (2013). 'Heritage as Improvement: Cultural Display and Contested Governance in Rural China', Modern China, 39 (4): 380-407.

Oakes, Tim, and Donald S. Sutton (2010). Faiths on Display: Religion, Tourism, and the Chinese State (Lanham: Rowman \& Littlefield).

Pendlebury, John (2015). 'Heritage and Policy', in The Palgrave Handbook of Contemporary Heritage Research, ed. by Emma Waterton and Steve Watson (New York: Palgrave Macmillan), 426-441.

Robertson, Ian J.M. (2012). Heritage from Below (Farnham, Surrey: Ashgate).

Shanghai Culture and Broadcasting Department (2010). 'Di'er pi shanghaishi feiwuzhi wenhua yichan xiangmu daibiaoxing chuanchengren tuijian biao' [Recommendation on Shanghai Municipality's second batch of the intangible cultural heritage representative transmitters program], http://www.ichshanghai.cn/userfiles/chuanchengrentuijianbiao(1).doc.

Silverman, Helaine (2011). Contested Cultural Heritage: Religion, Nationalism, Erasure, and Exclusion in a Global World (New York: Springer).

Smith, Laurajane (2006). Uses of Heritage (London: Routledge).

Smith, Laurajane (2015). 'Intangible Heritage: A Challenge to the Authorised Heritage Discourse?', Revista d'Etnologia de Catalunya, 40, http://www.raco.cat/index. php/RevistaEtnologia/article/download/293392/381920.

Smith, Laurajane, and Emma Waterton (2009). “The Envy of the World?": Intangible Heritage in England', in Intangible Heritage, ed. by Laurajane Smith and Natsuko Akagawa (London: Routledge), 289-302.

State Council (2005). 'Guowuyuan guanyu jiaqiang wenhua yichan baohu de tongzhi' [State Council notice on strengthening intangible cultural heritage protection], http://www.gov.cn/gongbao/content/2006/content_185117.htm. 
State Council (2008). 'Guojiaji feiwuzhi wenhua yichan daibiaoxing xiangmu daibiaoxing chuanchengren rending yu guanli banfa (caogao)' [Identification and management approach for representative national intangible cultural heritage items and transmitters (draft)], http://www.dlqzysg.com/index.php/ article/_id/285.

$\mathrm{Su}$, Xiaobo (2010). 'Urban conservation in Lijiang, China: Power Structure and Funding Systems', Cities, 27: 164-171.

Svensson, Marina (2006). 'In the Ancestors' Shadow: Cultural Heritage Contestations in Chinese Villages', Working Paper in Contemporary Asian Studies 17, Lund University.

Thompson, Simon (2006). The Political Theory of Recognition: A Critical Introduction (Cambridge: Polity).

Tunbridge, J.E. and G.L. Ashworth (1995). Dissonant Heritage: The Management of the Past as a Resource in Conflict (Chichester: John Wiley).

UNESCO (2003). 'Text of the Convention for the Safeguarding of the Intangible Cultural Heritage', http://www.unesco.org/culture/ich/index.php?lg=en\&pg=0ooo6.

Wang, Yi, and Bill Bramwell (2012). 'Heritage Protection and Tourism Development Priorities in Hangzhou, China: A Political Economy and Governance Perspective', Tourism Management, 33: 988-998.

Yan, Haiming (2015). 'World Heritage as Discourse: Knowledge, Discipline and Dissonance in Fujian Tulou Sites', International Journal of Heritage Studies, 21 (1): $65-80$.

Yu, Hua (2015). 'A Vernacular Way of "Safeguarding” Intangible Heritage: The Fall and Rise of Rituals in Gouliang Miao Village', International Journal of Heritage Studies, 21 (10): 1016-1035.

Zhu, Yujie (2014). 'Cultural Effects of Authenticity: Contested Heritage Practices in China', International Journal of Heritage Studies, 21 (6): 594-6o8.

Zhu, Yujie, and Na Li (2013). 'Groping for Stones to Cross the River: Governing Heritage in Emei', in Cultural Heritage Politics in China, ed. by Tami Blumenfield and Helaine Silverman (New York: Springer), 51-71.

\section{About the author}

Christina Maags, Lecturer in Chinese Politics, School of Oriental and Asian Studies (SOAS), University of London, UK 